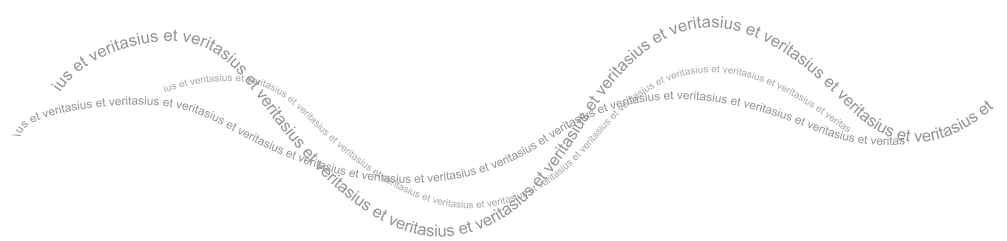

\title{
El servicio de provisión de agua potable y saneamiento como servicios esenciales
}

\section{The provision of drinking water and sanitation as essential services}

\begin{abstract}
Resumen: El autor parte por una revisión del concepto objetivo de servicio público, destacando como un elemento importante de este la idea de publicatio. A partir de ello, señala que no es posible entender el concepto de servicio público sin la presencia de la titularidad por parte del Estado. En este contexto, surge el concepto de servicio esencial como una técnica que armoniza las exigencias sociales y la concepción tradicional de servicio público. Finalmente, aterriza dichos conceptos para afirmar que la naturaleza del servicio de provisión de agua potable y saneamiento es de servicio esencial, desarrollando y aplicando sus principios al caso concreto.
\end{abstract}

Palabras clave: Servicio Público - Servicio Esencial - Servicio de Interés General - Publicatio - Derecho Administrativo Económico - Agua Potable y Saneamiento

\begin{abstract}
The author starts by revising the concept of public service, highlighting the idea of publicatio as an important element. With this taken into consideration, he points out that it is not possible to understand the concept of public service without the presence of ownership by the State. In this context, the concept of essential service arises as a technique that harmonizes social demands and the traditional conception of public service. All in all, these concepts are materialized to affirm that the nature of the service of drinking water and sanitation is of essential service, developing and applying its principles to the concrete case.
\end{abstract}

Keywords: Public Service - Essential Service - Service of General Interest - Publicatio - Economic Administrative Law - Drinking Water and Sanitation

$\left(^{*}\right.$ Estudiante del undécimo ciclo de la Facultad de Derecho de la Pontificia Universidad Católica del Perú. Ex miembro del Consejo Directivo y ex director de la Comisión de IUS $360^{\circ}$ de la Asociación Civil IUS ET VERITAS. Correo electrónico: erenesto.mendozaf@pucp.pe

${ }^{(* *}$ El autor agradece al Dr. Orlando Vignolo Cueva por la valiosa bibliografía recomendada, así como por los comentarios y sugerencias para concluir la elaboración del presente artículo.

$\left(^{* * *}\right)$ Nota del Editor: El artículo fue recibido el 25 de octubre de 2016 y aprobada su publicación el 26 de noviembre del mismo año. 


\author{
El servicio de provisión de agua potable y saneamiento como servicios \\ esenciales
}

The provision of drinking water and sanitation as essential services

\section{Introducción}

Uno de los conceptos más discutidos en la doctrina del Derecho Administrativo es el de servicio público. Ha sido constante el intento por forzar su adaptación a las nuevas exigencias sociales y económicas, controversia que hasta el día de hoy sigue vigente. Asimismo, los esfuerzos de la Unión Europea por clarificar dicho concepto llevaron a la creación de nuevas categorías jurídicas ${ }^{(1)}$, las cuales evidentemente obedecen al contexto europeo y responden a sus propias exigencias. Ante ello, consideramos que no resulta idóneo extrapolar dichos conceptos a la realidad peruana sin un análisis previo de los mismos; no obstante, el concepto de servicio esencial se presenta como una técnica que permite una colaboración entre agentes privados y públicos con el objetivo de garantizar la calidad y el acceso a los servicios públicos.

En cuanto a los servicios básicos para el desarrollo en sociedad, el agua potable y saneamiento se presenta como uno de las más importantes, no solo por su trascendencia sino por la problemática actual en relación a su prestación y las garantías que se brindan al respecto. Es así como consideramos inevitable aclarar la naturaleza de dicho servicio, lo cual servirá como partida para plantear, posteriormente, políticas y mecanismo que garanticen a cabalidad su acceso y calidad en el servicio, cumpliendo con la exigencia de que dicho servicio satisfaga las necesidades básicas en cada extremo del país.

\section{El tratamiento de los servicios públicos y esenciales en el Perú}

\subsection{La noción de servicio público}

El servicio público es una de las instituciones del derecho administrativo poco trabajada en la doctrina peruana, salvo contadas excepciones $^{(2)(3)}$. Sus inicios se remontan a la escuela francesa, donde la figura de León Duguit se presenta como la más relevante ${ }^{(4)}$ al analizar, dentro de la visión de su época, la

(1) Véase Martinez López-Muñiz, José Luis, 2001, "Servicio Público, Servicio Universal y "Obligación de Servicio Público," en La perspectiva del derecho comunitario: Ios Servicios Esenciales y sus Regímenes Alternativos". En: Os Caminhos da privatizacao da Administracao pública, IV Coloquio luso-espanhol de directo administrativo, Coimbra: Coimbra Editora, pp. 249-278.

(2) A nivel nacional, entre los autores que han trabajado seriamente el tema del servicio público destaca: (i) Zegarra Valdivia, Diego, 2011, "El servicio público. Fundamentos," (Lima: Palestra; o, (ii) Huapaya Tapia, Ramón, 2015, "Concepto y régimen jurídico del Servicio Público en el ordenamiento público peruano," en IUS ET VERITAS, 50, pp. 368-397. Asimismo, un reflexión constitucional ha sido trabajada por el profesor Danós Ordóñez, Jorge, 2008, "El régimen de los servicios públicos en la constitución peruana", en Themis, Revista de Derecho 55, pp. 255-264. Finalmente, una visión novedosa y la cual compartimos fue planteada por Baca Oneto, Víctor Sebastián, 2009, "Servicio Público, Servicio Esencial y Servicio Universal en el Derecho Peruano," en: Orlando Vignolo Cueva, coord., Lima: Teoría de los Servicios Públicos (Lima: Grijley), 355 - 388.

(3) Cabe resaltar que el interés por el estudio de los servicios públicos empezó a la par con la época de liberalización y privatización de los servicios; sin embargo, es necesario mencionar que en nuestro país no existe una noción histórica del servicio público.

(4) Consideramos que la primera visión moderna y que tiene influencia hasta nuestros días la dio León DUGUIT; sin embargo, resulta imperioso señalar la importancia que ha tenido el pensamiento del maestro francés Maurice Hauriou, ya que es este quien usa por primera vez el concepto jurídico del Servicio Público, según E. Pisier Kouchner, 1972, Le service public dans la théorie de l'état de Léon Duguit, Paris, Librerie Genérale de droit et de jurisprudence, pp. 18-19, citado por Zegarra Valdivia, Diego, "Del Servicio Público a los Servicios de interés general: la evolución del service public en el sistema jurídico," CDA, Revista de Derecho Administrativo 12, Tomo 1, (2012): 17. Es así como el concepto de poder público sirve como partida para la concepción de servicio público de Hauriou, donde la idea de prerrogativa - poder era el elemento esencial del régimen administrativo, a tal punto que el maestro francés llegó a decir que "mientras que el Derecho civil está fundado sobre la legalidad, el Derecho administrativo lo está sobre la prerrogativa" (M. Hauriou, "Précis élémentaire de Droit administratif," 5a ed., citado por Melián GIL, José Miguel, 2012, Lecturas de clásicos del derecho administrativo, Santiago de Compostela: Andavira, 91). 
Santos Ernesto Mendoza Flores

relevancia de la solidaridad social como base para su teoría del servicio público (Rodríguez-Arana 2013, 63). Es así como la escuela francesa busca construir una teoría general del derecho administrativo tomando como base el concepto de servicio público.

En esta línea, Duguit señala que "el Derecho Público es el derecho objetivo de los servicios públicos, no el derecho subjetivo de mando. Así como el Derecho Privado deja de estar fundado en el derecho subjetivo del individuo, en la autonomía de la persona misma y descansa en la noción de una función social que se impone a cada individuo, el Derecho Público no se funda en el derecho subjetivo del Estado, en la soberanía, sino que descansa en la noción de una función social de los gobernantes que tiene por objeto la organización y funcionamiento de los servicios públicos" (Rodríguez-Arana $2013,71)$. Es así como el maestro de la escuela francesa no solo considera al servicio público como la piedra angular de su construcción conceptual respecto al derecho administrativo, sino que concentra su teoría en la relación entre el poder público y la verdadera utilidad que generan las actividades públicas en la práctica.

Es así como lo que denominaremos el servicio público en sentido estricto, se construye sobre una base del derecho continental, lo cual sin duda es una de las contribuciones teóricas fundamentales para la noción del servicio público, donde Duguit "busca limitar al Estado dentro de la noción del Servicio Público, para lo cual cree necesario reemplazar aquellas teorías que estaban basadas en autolimitaciones por esta construida sobre la noción de un derecho objetivo" (Zegarra 2012, 17). No obstante, las condiciones actuales basadas en la industrialización y la necesidad del manejo de complejos servicios como el agua o la electricidad, exigen no desconocer las tradicionales teorizaciones sobre los servicios públicos, sino redescubrir dicha noción en la búsqueda de técnicas que ayuden a su tratamiento de las formas más óptimas.

Como venimos señalando, cierto sector de la doctrina moderna ha propuesto que la concepción tradicional de las actividades calificadas como "servicio público" ha tenido que evolucionar a conceptos modernos como los relacionados al estado garante(5), donde la función del Estado es la de prever y asegurar el cumplimiento de las condiciones necesarias para la satisfacción de las necesidades de la sociedad, pues es irrefutable que los últimos años exigen la intervención de privados en dichas actividades.

Es así como el maestro Gaspar Ariño, al referirse a la noción de servicio público, señala que "es inútil empeñarse en embalsamarlo, como intentan los franceses, por si de esta forma pudiéramos mantenerlo vivo. La situación es otra, casi la inversa. Son los hechos los que mandan, más que la ideología o la política y hoy han cambiado radicalmente los presupuestos económicos y sociales también los políticos y culturales - sobre los cuales esta institución nació y se desarrolló felizmente" (2004, 613). El profesor Ariño hace mención a que los cambios sociales y el deterioro de la administración pública respecto a las técnicas prestacionales de los llamados servicios públicos, obligan a repensar un nuevo concepto del mismo, que va acompañado de un nuevo modelo de regulación económica.

La tradición jurídica contemporánea ha buscado mantener viva la categoría del servicio público en casi todos sus extremos, siempre tratando de encontrar la fórmula ideal ante las necesidades del mundo contemporáneo, donde cada vez más irrumpe la exigencia de la actividad privada para colaborar en el deber de satisfacer las necesidades generales de la sociedad. En este contexto, el concepto de servicio público ha sido objeto de "novedosos" tratamientos y reformulaciones (ahora ya "clásicos"), dentro de los que rescatamos lo mencionado por el profesor Luciano Parejo,

(5) Véase Esteve Pardo, José, “La Administración Garante. Una aproximación”, Revista de Administración Pública 197, (mayoagosto 2015: 11-39. En el Perú, dicha postura se esboza en Huapaya Tapia, Ramón $(2011,373)$ 


\section{El servicio de provisión de agua potable y saneamiento como servicios esenciales}

The provision of drinking water and sanitation as essential services

quien señala una doble identificación: primero, el concepto "formal, subjetivo, orgánico o estricto", donde lo que predomina es la "técnica organizativa de la provisión o prestación de este"; $y$, en segundo lugar, su concepto "amplio, objetivo o funcional", donde lo que se identifica son "las notas de continuidad, regularidad, igualdad de acceso y trato, universalidad, adecuación al progreso técnico, control de precio, etcétera" (Parejo 2004, 64).

En este orden de ideas, el servicio público no es una técnica capaz de soportar toda cantidad de modificaciones en su concepto, sino lo que se debe buscar es adecuar sus propios elementos a la actualidad y a las exigencias naturales de la época. El servicio público se compone de dos elementos: (i) el interés general; y, (ii) la publicatio.

Los esfuerzos por objetivizar el concepto de servicio público ha llevado a la idea de extrapolar técnicas comunitarias a otros contextos, así como los conceptos de interés general, servicios de interés económico general o servicio universal(6). El maestro José Luis Martínez López-Muñiz, señala con agudez que "la polémica y el notable grado de dificultad para entender que con frecuencia se perciben en relación con la suerte de los llamados servicios públicos en la construcción europea, están clamando por la fijación de un nuevo sistema conceptual y terminológica que contribuya a la clarificación y el acuerdo" $(2001,268)$.

Las técnicas antes mencionadas han nacido en el contexto comunitario, y son propias de las exigencias y necesidades de dicha sociedad. No faltaría quien señale que sus definiciones y práctica se agoten en el papel; sin embargo, su existencia fue vital en un contexto político complicado en el terreno europeo, donde se discutía la utilidad de la técnica del servicio público. Asimismo, las mencionadas técnicas tienen una naturaleza de apoyo a la del servicio público, donde nace la necesidad de una clarificación del concepto de publicatio.

A pesar de esta discusión extranjera, en el Perú primó la tesis de la sobrevivencia del servicio público. Asimismo, se trasladó el concepto de "nuevo servicio público", el cual tiene un carácter meramente objetivo y económico.

\subsection{Una aproximación al concepto de la publicatio}

La pubicatio es una de las nociones fundamentales del derecho público de los últimos años, específicamente, a lo que derecho administrativo económico refiere. Su relación con el concepto objetivo de servicio público y su férrea vinculación con la iniciativa y actividad privada para gestionar cierto servicio, ha provocado que se genere toda una discusión sobre la vigencia de dicho concepto y su utilidad en la actualidad.

En principio, la declaración como pública de determinada actividad (la llamada publicatio), se configura como la "exclusión" de los privados para realizar dicha actividad, pues a pesar de que el servicio se otorgue en concesión a un privado, la titularidad será, de acuerdo a esta línea argumentativa, de carácter público. Asimismo, ello no significa que los privados no realicen dicha actividad, pero "dado el compromiso político implicado en la prestación, así como la necesidad de satisfacer los requerimientos colectivos, históricamente se prefirió someterlo a un régimen jurídico de derecho público" (Ochoa 2013, 106).

Como señala el profesor Juan Carlos Cassagne, el fenómeno de la privatización conllevó a que se intente suprimir el concepto de publicatio del servicio público, "como si esta figura fuera la causante del régimen autoritario y estatista que llegó a caracterizar el servicio público en determinadas épocas históricas" (1996, 103). Coincidimos con el autor en mención cuando este afirma que la publicatio no confiere derecho real alguno al Estado, postura con la que también concuerda cierto sector de la doctrina nacional(7).

(6) Estas definiciones comunitarios son explicadas brillantemente por Martinez López-Muñiz, José Luis, 2011. Asimismo, el profesor peruano Ramón Huapaya Tapia hace un conciso recuento de dichas técnicas en su artículo "Concepto y régimen jurídico del Servicio Público en el ordenamiento público peruano" (2015, 377-378)

(7) El profesor Jorge Danós (Danós Ordoñez 2008, 255-264) afirma: "conforme señala el profesor Juan Carlos Cassagne, 


\section{Santos Ernesto Mendoza Flores}

Es así como el concepto de publicatio o publificación como declaración de una actividad o sector como servicio público, no se agota en la titularidad absoluta por parte del estado, sino que va íntimamente relacionado con el concepto de subsidiariedad; sin embargo, este análisis excede los límites del presente trabajo.

En este orden de ideas, la noción de publicatio debe permanecer como requisito esencial del servicio público, el cual es una técnica que la administración puede utilizar siempre que sea necesario. Además, el fenómeno de la privatización no conlleva a una exclusión o intento de desechar la noción de publicatio, ya que diversas técnicas privatizadoras pueden plantearse en armonía práctica con la declaración legal de titularidad de cierta actividad o sector, es decir, la reserva del mismo por parte del Estado.

Finalmente, cabe plantear la interrogante de si realmente existe publicatio en el Perú, debido a que como reserva se ve limitada por el artículo 61 de la Constitución Política del Perú. Si bien este cuestionamiento excede los límites del presente trabajo, dicho cuestionamiento resulta necesario para comprender a profundidad el concepto del servicio público.

\subsection{El servicio público en la doctrina peruana}

Como señala el profesor Diego Zegarra, en el Perú no existe una tradición jurídica del estudio del servicio público como doctrina, a lo que agregamos que su estudio se empezó muy tarde y no se llegaron a interiorizar conceptos originados en otras realidades y con otras exigencias.

Ahora, respecto a una construcción del concepto del servicio público, el mismo autor señala tajantemente que "a propósito de que una actividad sea considerada servicio publico, como se desprende de la legislación revisada, es el legislador peruano el que establece dicha calidad, dependiendo ello fundamentalmente del interés general, elemento este ultimo cuyo carácter es evidentemente variable en el tiempo y en el espacio" (Zegarra 2012, 351)
En esta línea, el profesor Jorge Danós asevera que "el servicio público también puede ser entendido como un régimen normativo especial, aplicado a determinadas actividades expresamente calificadas por el legislador por su carácter esencial para la satisfacción de las necesidades públicas indispensables para la colectividad, que se resume en un conjunto de principios que constituyen fuentes de obligaciones jurídicas para los prestadores o gestores de los servicios y simultáneamente potestades para las entidades estatales encargadas de velar por su cumplimiento" (2008, 261-262).

Destacamos el análisis constitucional que realiza el profesor Danós, dentro del cual resalta la importancia de la jurisprudencia al momento de señalar los principios fundamentales de los servicios públicos, lo cual se constituye como un avance en nuestro afán por integrar conceptos en pos de construir una definición de servicio público acorde a nuestro tiempo. Dicha jurisprudencia ${ }^{(8)}$ señala:

“(...) existen una serie de elementos que en conjunto permiten caracterizar, en grandes rasgos, a un servicio como público y en atención a los cuales, resulta razonable su protección como bien constitucional de primer orden y actividades económicas de especial promoción para el desarrollo del país. Estos son:

a) Su naturaleza esencial para la comunidad.

b) La necesaria continuidad de su prestación en el tiempo.

la declaración por ley de una actividad económica como servicio público, también denominada publicatio: “(...) no implica atribuir al Estado derecho real alguno. En rigor, ella traduce la incorporación de una actividad del sistema de derecho público y tan sólo expresa la decisión estatal de que una determinada actividad estatal se sujete a las potestades administrativas mediante un régimen especial", en su artículo "El régimen de los servicios públicos en la Constitución Peruana".

(8) STC 00034-2004-PI/TC, de fecha 15 de febrero de 2005. Caso medio pasaje. Fundamento 40. 


\section{El servicio de provisión de agua potable y saneamiento como servicios esenciales}

The provision of drinking water and sanitation as essential services

c) Su naturaleza regular; es decir, que debe mantener su estándar mínimo de calidad.

d) La necesidad de que su acceso se dé en condiciones de igualdad".

El profesor Danós se sirve de dicho desarrollo jurisprudencial para concluir explicando breve pero consistentemente los principios constitucionales del servicio público en nuestra tradición: (i) principio de igualdad o generalidad, (ii) principio de continuidad, (iii) principio de regularidad, (iv) principio de mutabilidad o adaptabilidad a las condiciones técnicas (Danós Ordoñez 2008, 262-264).

Por otro lado, el profesor Ramón Huapaya, basándose en autorizada doctrina española defiende la tesis del garantismo, llegando incluso a señalar que "bajo el principio de subsidiariedad hay que distinguir entre actividades prestacionales (servicios públicos sociales) y actividades de garantía estatal (servicio publico económico)" (Huapaya 2015, 396). Cabe resaltar la importancia de la doctrina garantista dentro de la evolución del concepto de servicio público; no obstante, resulta incompresible concebir este concepto sin la publicatio o titularidad pública.

Consideramos que la técnica del servicio público ha tratado de ser moldeada a las distintas exigencias de la sociedad; no obstante, existen técnicas que funcionarían como alternativa en vista de que dicho concepto no armonice con las necesidades económicas o con determinada técnica de inversión.

Al respecto, las aproximaciones del profesor Víctor Baca sobre la actual noción de servicio público y la relación propuesta con otras técnicas, resultan interesantes y necesarias debido a que inserta conceptos no estudiados con claridad en nuestra tradición jurídica. En este sentido, nuestro análisis concuerda totalmente con la afirmación que realiza el profesor Baca, cuando señala que "creemos que el título jurídico general sería el servicio esencial, mientras que el servicio público (con publicatio) sería una técnica concreta para lograr su realización. Pero, claro está, no es la única, de modo que reconocida la esencialidad de un servicio, es posible establecer un régimen especial para él, con obligaciones para los particulares que de otro modo no existirían, y reconociendo la posibilidad de intervención directa de la administración en la prestación del servicio". (Baca 2009, 365). En esta línea, consideramos que esta línea de pensamiento forja una escuela del servicio público peruano, la cual sigue las ideas, principalmente, de Luis José Martínez López-Muñiz.

En esta línea, la objetivación del concepto de servicio público ha costado el intento de supresión de la noción de publicatio, cuando esta un elemento base del mismo. Ante dicho problema, y como también lo mencionó Martínez López-Muñiz, la esencialidad del servicio surge como una alternativa para su gestión y un tratamiento que no afecte el tan maltratado concepto de servicio público.

El maestro Juan Carlos Cassagne ya había advertido que dos elementos fundamentales del servicio público eran su carácter esencial y la publicatio (Cassagne 1996, 100). De esta forma, el garantismo es un concepto necesario para el efectivo desarrollo de las industrias y alcance de los servicios; sin embargo, es muy discutible que lleve consigo la redefinición del concepto del servicio público a un extremo que perjudica su propia naturaleza jurídica.

La entrada del "servicio esencial" como la realidad objetiva del servicio público (Baca 2009, 362) se muestra como el concepto jurídico que puede armonizar las nociones de servicio público y garantismo. Dicho problema no es reciente, pues la necesidad de su clarificación llevó a Martínez LópezMuñiz a afirmar: "Venimos desde hace algún tiempo haciendo propuestas en este sentido, que puedan integrar la noción en ascenso del servicio universal con la específicamente comunitaria del servicio de interés económico general, y con la constitucional española del servicio esencial, resituando la de servicio público en el lugar más limitado que en realidad debe corresponderle" (López-Muñiz 2001, 268).

En este contexto la noción de servicio esencial "se define por su vinculación a la satisfacción 
Santos Ernesto Mendoza Flores

de las necesidades fundamentales de los ciudadanos y al ejercicio de sus derechos fundamentales, por lo que debe ser prestado en condiciones de igualdad, garantizándose un acceso universal a un servicio de calidad, prestado en condiciones de regularidad y continuidad, según los parámetros de la evolución técnica y científica en cada ámbito geográfico"(9) (Baca 2009, 362). Es así como estamos frente a un servicio esencial como alternativa, siendo este un escenario donde el servicio público sigue tan vigente como hace dos décadas, pero ahora se sirve de técnicas como el servicio esencial o el servicio universal como categoría idónea donde el concepto de servicio público se agota.

El tratamiento de la doctrina más relevante ha considerado ciertas diferencias entre el servicio esencial y el servicio universal, no obstante, consideramos que se tratan de conceptos homólogos ${ }^{(10)}$, diferenciables forzosamente en contextos de vital interés social. Al respecto, Baca señala que "las Ilamadas obligaciones de "servicio público", que en realidad deberían ser del "servicio esencial", y que son llamadas de "servicio universal" por aquellos que restringen la noción de este último a los casos en donde la competencia es insuficiente (...) [cuando] lo cierto es que el "servicio universal" no se define por la falta de competencia, sino porque el Estado debe garantizarlo, incluso si la competencia no lo satisface" (Baca 2009, 374). Además, lo esencial implica, intrínsecamente, una exigencia de prestación universal, como es el caso de los servicios de saneamiento - agua potable, o del transporte público.

Finalmente, el servicio público es una figura y herramienta del derecho administrativo necesaria cuando existan situaciones de última ratio, es decir, donde se requiera acudir al concepto de la publificación o publicatio. Antes, existen técnicas como el servicio esencial (que se puede asemejar al concepto de servicio de interés de interés general(11) del derecho comunitario) o servicio universal - lo cual hemos considerado conceptos homólogos - que dado que no exige la titularidad administrativa, existe un reconocimiento de la libertad de empresa y la iniciativa privada que claramente conlleva a que no se deforme el concepto de servicio público en la búsqueda por moldear dicha técnica a las exigencia contemporáneas.

\section{El servicio de agua potable y saneamiento en el Perú}

\subsection{Marco jurídico y acceso al servicio} Dentro de los diversos servicios de necesidad vital para la sociedad, uno de los que más interés despierta es el agua. La problemática generada en torno a su acceso, la escasez en muchas comunidades y las diversas iniciativas para mejorar su gestión se presentan como situaciones de alta preocupación a nivel mundial.

La situación peruana no es ajena a dicha discusión, "es por ello que la normativa aplicable ha procurado establecer reglas claras que permitan el progreso de los servicios en cuestión sobre la base de los beneficios que aportan" (Cairampoma y Villegas 2016, 232). En este sentido, la recientemente publicada Ley Marco de la Gestión y Prestación de los Servicios de Saneamiento, aprobada mediante Decreto Legislativo N. ${ }^{\circ} 1280$ (en adelante, la "Ley Marco"), señala como principios rectores:

(9) En este sentido, el maestro José Luis Martínez López-Muñiz, señala a propósito del concepto de servicio esencial, que "se trata de actividades prestacionales de bienes y servicios a los ciudadanos de carácter vital o básico para la satisfacción o el ejercicio de los derechos fundamentales y el consiguiente desarrollo de una vida digna, mínimamente acorde con las condiciones espacio-temporales del desarrollo o del progreso social, y que, por ello, no pueden dejar de tener un destino universal y ser efectivamente accesibles a todos en condiciones básicas de igualdad, asegurándose su suficiente regularidad y continuidad, bajo unos patrones de calidad determinados, con adaptación progresiva a la evolución técnica y a los cambios sociales" (López-Muñiz 2001, 269).

(10) Al respecto, el profesor Víctor Baca Oneto afirma que "en realidad, el servicio universal no es más que el servicio esencial, aunque poniéndose énfasis en una de sus características: la universalidad de su acceso". (Baca 2009, 368).

(11) Sobre las diferencias, la doctrina nacional ha sido muy clara (Baca Oneto 2009). 


\section{El servicio de provisión de agua potable y saneamiento como servicios esenciales}

The provision of drinking water and sanitation as essential services

(i) acceso universal; (ii) esencialidad; (iii) inclusión social; (iv) autonomía y responsabilidad en la gestión empresarial; (v) independencia en el manejo de los recursos financieros y patrimonio; (vi) responsabilidad, transparencia y rendición de cuentas de las entidades sectoriales (vii) buen gobierno corporativo y rendición de cuenta de los prestadores; (viii) eficiencia; (ix) equilibrio económico y financiero; $y,(x)$ protección del ambiente y uso eficiente del agua.

Asimismo, el legislador al referirse al servicio de saneamiento incluye, según el artículo 2 de la Ley Marco: (i) servicio de agua potable; (ii) servicio de alcantarillado sanitario; (iii) servicio de Tratamiento de Aguas Residuales para disposición final o reúso; y, (iv) servicio de disposiciones sanitarias de excretas.

Los principios señalados indican la búsqueda por garantizar un servicio no solo asequible, sino que cubra las necesidades básicas en todos los extremos del país. Esta noción se basa la declaración de legislador como un servicio universal, lo cual conlleva a sostener los principios del servicio esencial mencionados, lo cual será materia de análisis del siguiente apartado.

Al respecto, el maestro Antonio Embid Irujo señaló factores respecto al crecimiento, sistemas e investigación sobre el agua que luego de más de una década aún tienen vigencia, como que "el valor primordial del medio ambiente, de la conservación de los recursos, de la gestión de la demanda, de la utilización de los medios económicos para la gestión de un recurso escaso, de la formación de nuevas tecnologías, de la necesidad de incrementar el gasto de investigación y desarrollo en el ámbito del agua" (Embid 2001, 90), son conceptos que siempre debemos tener presente al establecer políticas e iniciativas respecto al uso y tratamiento del agua.

En este sentido, dentro del contexto peruano de prestación del servicio de agua potable y saneamiento, la Superintendencia Nacional de Servicios de Saneamiento (SUNASS) cumple un rol fundamental respecto a la supervisión de los operadores en dicho mercado. Así, el artículo 7 de la Ley Marco señala que la función de la SUNASS es "garantizar a los usuarios la prestación de los servicios de saneamiento en el ámbito urbano y rural, en condiciones de calidad, contribuyendo a la salud de la población y a la preservación del ambiente". Dicha supervisión se desarrolla en función a las entidades prestadoras de servicios de saneamiento (EPS), entre las que destacan el Servicio de Agua Potable y Alcantarillado de Lima S.A. (SEDAPAL), Agua de Tumbes S.A. (ATUSA) y Entidad Prestadora de Servicios de Saneamiento Grau (EPS Grau) (Cairampoma y Villegas 2016, 238).

Actualmente, el alcance de los servicios de agua potable y saneamiento no es el adecuado, debido a que "no existe una política específica sobre servicio o acceso universal" (Cairampoma y Villegas 2016, 236). Al respecto, consideramos pertinente señalar que "en cuanto a las políticas claves del Estado, además de la planificación nacional (...) es muy importante también el tema de la promoción de las inversiones, la apertura comercial y la ampliación de los mercados interno y externo, las políticas de competencia y protección del consumidor, sin dejar de lado el sostenido proceso de las capacidades de los actores de la política pública" (Durand 2012, 223).

Es así como la idea general sobre el servicio del agua, debido a las bajas coberturas del mismo, se concentra en la calidad del servicio por debajo de estándares mínimos necesarios para satisfacer las diversas necesidades que implica el uso del agua. En este marco, debe existir una completa colaboración entre las EPS, la SUNASS y las autoridades respectivas (a nivel local, regional o central), ya que solo así se puede garantizar la efectiva prestación del servicio.

3.2. La provisión de agua potable y saneamiento como servicios esenciales Luego de establecer la diferencia entre el servicio público y el servicio esencial o universal, el cual se resume en la posibilidad del segundo como técnica que permite una gestión y tratamiento más amplio de las actividades o servicios, no teniendo que limitarse a la titularidad de la administración para cubrir los alcances o coberturas de dichos servicios. 
Santos Ernesto Mendoza Flores

Bajo esta premisa, la provisión del servicio de agua potable y saneamiento, que estamos considerando como un sistema integrado que no solo abarca la provisión de agua potable, sino de los servicios que señala el artículo 2 de la Ley Marco, se ha caracterizado por un proceso histórico de desarrollo cuya primera etapa, entre 1980 y 1990 se ha caracterizado por un incremento en la cobertura del servicio de agua potable en la población urbana en $11 \%$ (de $63 \%$ a $74 \%$ ) y de saneamiento en $2 \%$ (de $56 \%$ a $58 \%$ ), y SEDAPAL, específicamente, llegó a un $80 \%$ de cobertura (Oblitas 2010,10). Al 2015, el acceso al agua potable en el ámbito urbano es aproximadamente $91 \%$ de la población y un $82 \%$ de acceso en el caso de saneamiento (OMS y UNICEF 2016, 70-71).

La preocupación por garantizar el acceso al servicio es evidente. Luego de más de 25 años de políticas y esfuerzos, gran parte de la población peruana urbana no cuenta con un acceso universal al servicio de agua potable y saneamiento. La problemática se acrecienta cuando nos referimos a la población rural, la cual al 2015 se tiene un acceso aproximado de $69 \%$ referido al agua potable y de $53 \%$ referido al saneamiento (OMS y UNICEF 2016, 70-71). Es en este contexto que "el sector requiere el desarrollo de una política financiera que introduzca los incentivos necesarios para la sostenibilidad de las inversiones y promueva, al mismo tiempo, la eficiencia en la prestación de los servicios y la incorporación al servicio de los más pobres" (Marmanillo 2006, 341). Al respecto, un interesante avance fueron los subsidios en las tarifas de agua y alcantarillado de SEDAPAL; sin embargo, si bien "la estructura tarifaria de SEDAPAL subsidia a una cantidad significativa de usuarios conectados no pobres [el] principal problema es que no se identifica adecuadamente a los que deben ser beneficiarios de los subsidios" (Alza 2012, 262). Este sistema subsidios basado en razones de equidad no debe perder de vista la razonabilidad y los criterios posibles de eficiencia (Quintana 2012, 83).

Entrando al final del presente trabajo, luego de haber desarrollado la diferencia entre servicio público y servicio esencial, así como la importancia y problemática que se presenta en torno al acceso al servicio de agua, consideramos apremiante concluir la naturaleza de dicho servicio, lo que será necesario para determinar las políticas e iniciativas para su acceso a cada extremo del país.

En primer lugar, puede pensarse que el agua es una actividad de interés general. Al respecto, Martínez López-Muñiz señala que muchas actividades pueden o no ser de interés general y servir de justificación para actuaciones públicas, pero que no tienen el requisito de lo esencial. Menciona ejemplos como el teatro o actividades deportivas, que pueden ser de interés general pero no esenciales (Baca 2009, 364).

Además, consideramos que el agua es un servicio que necesita iniciativas privadas que estén a la altura de invertir en mecanismos que garanticen el acceso y cobertura universal de dicho servicio. En este aspecto, la figura del servicio público no se presenta como la idónea debido a su carácter meramente restrictivo, donde la titularidad pública del servicio de agua potable y saneamiento se presenta como un límite al pleno desarrollo del sector.

Por otro lado, la técnica del servicio esencial permite que el Estado intervenga cuando la dinámica propia del mercado no sea suficiente para satisfacer la cobertura general del servicio, resguardando los principios fundamentales de dicho servicio, tales como continuidad, regularidad, entre otros. Esta característica se fundamenta en el carácter universal del servicio esencial, pues si bien no existe una titularidad propiamente dicha por parte de la administración pública, esta se ve en la obligación de intervenir con al finalidad de cubrir dicho servicio. Así, la esencialidad del servicio conlleva al carácter universal del mismo ${ }^{(12)}$.

(12) Al respecto, el maestro José Luis Martínez López-Muñiz señala: "cada día se habla más, por otra parte, del servicio universal, también como consecuencia de su asunción por la terminología de los organismos comunitarios y precisamente en el proceso de liberalización en marcha. Se utiliza esta expresión para aludir a un conjunto de "determinadas prestaciones esenciales" 


\section{El servicio de provisión de agua potable y saneamiento como servicios esenciales} The provision of drinking water and sanitation as essential services

En esta línea, la universalidad no es el único requisito que define al servicio del agua potable y saneamiento como uno esencial. Como ya hemos mencionado previamente, los principios característicos de un servicio esencial son: (i) universalidad; (ii) accesibilidad en condición de igualdad; (iii) regularidad y continuidad; (iv) calidad; e, (v) innovación tecnológica. El servicio de agua potable y saneamiento debe necesariamente contar con cada uno de estos elementos, configurándose como servicio esencial.

Sobre la universalidad hemos comentado su intrínseca relación con la esencialidad del servicio, que se configura bajo las garantías de los principios que le prosiguen. El segundo principio es el acceso al servicio, lo cual significa, básicamente, la posibilidad de poder contar con el servicio de agua potable y saneamiento para satisfacer nuestras necesidades básicas. Actualmente, el acceso al servicio del agua depende mucho de la ubicación geográfica y el nivel económico de determinados lugares, ello evidencia la brecha de accesibilidad existente entre los ámbitos urbanos y rurales, como previamente hemos mencionado.

Es así como el acceso al servicio no se agota en la posibilidad de beneficiarse del mismo, sino que necesariamente tiene que ser en condiciones de igualdad. Entendemos este principio desde una perspectiva de no discriminación, es decir, queda rotundamente prohibida la negación del acceso a dicho servicio, ello fundamentándose en su carácter universal. Así, tanto una persona natural como empresas tienen el mismo derecho de acceso al servicio, ya sea para satisfacer necesidades básicas, como para construcción de infraestructuras de envergadura que requieran el uso del servicio para su mantenimiento.

Por otro lado, la regularidad y continuidad en la prestación del servicio se configura como característica fundamental de un servicio esencial. En el caso del agua potable y saneamiento, entendemos ello como la prestación constante e ininterrumpida del servicio, aún en condiciones geográficas complicadas, pues la universalidad del servicio requiere que obligatoriamente este se preste con todas las garantías. Sin este principio, el servicio de agua potable y saneamiento solo sería brindado esporádicamente, vulnerando profundamente la esencialidad del mismo.

Un cuarto principio del servicio esencial es la calidad del mismo. Entendemos por calidad el nivel de satisfacción por parte del usuario respecto al servicio. Es así como los principios cumplen un rol integrador, pues la calidad depende a su vez de la continuidad, regularidad y acceso. Cuando el servicio es capaz de satisfacer las diversas exigencias de cada uno de nosotros, sea en el ámbito urbano o rural, se puede hablar, a grandes rasgos, de que se cumple la calidad del servicio. Sin este principio, la prestación del servicio de agua potable no cumpliría su razón de ser, pues resulta ilógico ejecutar planeamientos y políticas generales cuando el resultado será un servicio mediocre.

Como quinto y último principio, cabe señalar la innovación tecnológica, lo que el maestro Martínez López-Muñiz denomina "adaptación progresiva a la evolución técnica y a los cambios sociales" (López-Muñiz 2001, 362). Básicamente, el servicio de agua potable y saneamiento necesita adecuarse a los distintos avances tecnológicos respecto al tratamiento de aguas así como los mecanismos de alcantarillado y saneamiento en general.

\footnotetext{
"específicas" de determinada "calidad", en las que debe garantizarse "el acceso de todos a un precio asequible". Lo mismo, a la postre, que el servicio esencial, aunque el adjetivo universal aluda más directa y expresivamente a esa accesibilidad general. Pero la exigencia de ésta se justifica precisamente en la esencialidad del servicio que le hace indispensable. En el n. 33 de la Comunicación de 1996, se llega a hablar explícitamente de obligaciones de servicio universal o de servicio público como expresiones que significan lo mismo. El servicio universal no es, pues, sino aquel tipo de servicio en el que debe garantizarse - precisamente por su esencialidad - que llegue a todos, o que puedan usarlo, y obviamente con una calidad y a un precio que permita precisamente a todos ese uso efectivo y bajo básicas condiciones de igualdad". (LópezMuñiz 2001, 271-272).
} 


\section{Santos Ernesto Mendoza Flores}

Finalmente, la naturaleza del servicio de agua potable y saneamiento es propia de una que permita establecer un mercado y que diversos actores intervengan en la búsqueda de elevar la calidad y el alcance del servicio. Asimismo, el carácter garantista de la administración cumple un rol determinante en el esquema de la prestación del servicio, procurando que las EPS cumplan cabalmente la esencialidad del mismo. Es en este orden de ideas, que es imposible concebir al servicio de agua potable y saneamiento sin un acceso en condiciones de igualdad, continuidad y regularidad, calidad, inclinado a los cambios tecnológicos y, sobre todo, universal, siendo por ello que se trata de un servicio esencial.

\section{Conclusiones}

El servicio público es un concepto propio de la tradición europea con fuerte arraigo en el poder de la administración pública para el manejo de los recursos. Somos conscientes de que en el derecho existen categorías que no son exactas y su naturaleza dependerá de los cambios sociales o los avances jurídicos al respecto.

Es este sentido, el concepto de servicio público depende fundamentalmente, como se planteo en su idea tradicional, de la noción de publicatio, es decir, de la declaración de una actividad o sector como reservada para la administración. La discusión académica revisada planteó la posibilidad de un "nuevo servicio público", donde se acude a la figura de un "estado garante" y se prescinde del concepto de publicatio.

En ese contexto, la noción de servicio esencial surge como una técnica que permite armonizar las exigencias propias del contexto contemporáneo con la definición tradicional del servicio público, así consideramos que la publicatio es un requisito fundamental del mismo. Cabe resaltar que la técnica del servicio esencial no conlleva a la desaparición del servicio público, ya que ambos son conceptos distintos con las que la administración pública cuenta para contextos determinados.

Finalmente, en una realidad donde se necesita invertir y reorganizar la prestación del servicio de agua potable y saneamiento, la reserva de la titularidad de dicho servicio no resulta un escenario posible. En este caso, el concepto de servicio esencial surge como una técnica que define realmente la naturaleza del servicio de agua potable y saneamiento, destacando entre sus principios la igualdad en el acceso y la universalidad de la prestación.

\section{Referencias Bibliográficas}

Alza Barco, Carlos. 2012. Sostenibilidad y subsidios en las tarifas de agua y alcantarillado de SEDAPAL: hoja de ruta para su mejora. CDA Revista de Derecho Administrativo 12: 257-263.

Ariño Ortiz, Gaspar. 2004. Nuevo servicio público y regulación económica. En: Principios de Derecho Público Económico, Lección Decimoséptima, Lima: ARA.

Baca Oneto, Víctor Sebastián. 2009. "Servicio Público, Servicio Esencial y Servicio Universal en el Derecho Peruano". En Teoría de los Servicios Públicos, coords. Orlando Vignolo Cueva, Orlando Lima: Grijley, 355 - 388.

Cairampoma Arroyo, Alberto y Villegas Vega, Paul. 2016. El acceso universal al agua potable. La experiencia peruana. Revista de Derecho PUCP 76: 229-249. https://doi. org/10.18800/derechopucp.201601.009

Cassagne, Juan Carlos. 1996. El resurgimiento del servicio público y su adaptación en los sistemas de economía de mercado (Hacia una nueva concepción). Revista de Administración Pública 40 (mayo - agosto).

Danós Ordóñez, Jorge. 2008. El régimen de los servicios públicos en la constitución peruana. Themis, Revista de Derecho 55: 255-264.

Durand Carrión, Julio. 2012. El acceso al agua como un derecho humano universal y la necesidad de una política pública más allá de las cuestiones regulatorias. CDA, Revista de Derecho Administrativo 12: 223-232. 


\section{El servicio de provisión de agua potable y saneamiento como servicios esenciales \\ The provision of drinking water and sanitation as essential services}

Embid Irujo, Antonio. 2001. Evolución del derecho y de la política del agua en España. Revista de Administración Pública 156 (septiembre-diciembre).

Esteve Pardo, José. 2015. La administración garante. Una aproximación. Revista de Administración Pública 197 (mayo-agosto): 11-39. https://doi.org/10.18042/cepc/ rap.197.01

Huapaya Tapia, Ramón. 2015. Concepto y régimen jurídico del Servicio Público en el ordenamiento público peruano. Ius Et Veritas 50 (julio): 368-397.

Marmanillo, Iris. 2006. Agua Potable y Saneamiento. En Perú: La oportunidad de un país diferente. Lima: Banco Mundial. Editado por Giugale, Marcelo M.; Fretes-Cibils, Vicente; Newman, John L, 325-351.

Martínez López-Muñiz, José Luis. 2001. Servicio Público, Servicio Universal y "Obligación de Servicio Público" en la perspectiva del Derecho Comunitario: los Servicios Esenciales y sus regímenes alternativos. En Os Caminhos da privatizacao da Administracao pública, IV Coloquio lusoespanhol de directo administrativo. Coimbra: Coimbra Editora. 249-278.
Melián Gil, José Miguel. 2012. Lecturas de clásicos del derecho administrativo, Andavira: Santiago de Compostela.

Oblitas De Ruiz, Lidia. 2010. Servicios de agua potable y saneamiento en el Perú: beneficios potenciales y determinantes de éxito. Santiago de Chiles: Comisión Económica para América Latina y el Caribe - CEPAL.

Ochoa Cardich, César. 2013. El servicio público en la Constitución de 1993. En Pensamiento Constitucional 18.

Organización Mundial de la Salud \& UNICEF. 2016. Progresos en materia de saneamiento y agua potable. Informe de actualización 2015 y evaluación del ODM. Panámicas para Latinosan.

Parejo Alfonso, Luciano. 2004. Servicios Públicos y Servicios de Interés General: la renovada actualidad de los primeros.

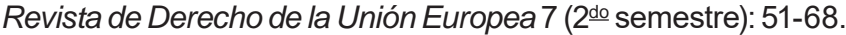

Quintana Sánchez, Eduardo. 2012. Naturaleza y efectos de los subsidios en Servicios Públicos. CDA, Revista de Derecho Adminsitrativo 12: 75-83.

Rodríguez-Arana Muñoz, Jaime. 2013. Sobre las transformaciones del Derecho Público, de León Duguit. Revista de Administración Pública. (enero-abril): 61-100.

Zegarra Valdivia, Diego. 2012. Del Servicio Público a los servicios de interés general: la evolución del service public en el sistema jurídico. CDA, Revista de Derecho Adminsitrativo 12: 13-43. .2005. El servicio público. Fundamentos. Lima: Palestra. 